\title{
Exantema generalizado y tromboembolismo pulmonar tras la administración de la vacuna AD26.COV2-S en paciente con antecedente reciente de infección por SARS-COV2 (COVID-19): reporte de un caso
}

\author{
Generalized exanthema and pulmonary embolism after the administration of AD26.COV2-S \\ vaccine in a patient with recent history of SARS-COV2 infection (COVID-19): a case report
}

\author{
Fernando Maroto Piñeiro, Lucía González González, Judith Álvarez Otero, Javier de la Fuente Aguado \\ Servicio de Medicina Interna Hospital Ribera POVISA
}

\section{RESUMEN}

La reciente aparición de multitud de vacunas contra la infección por SARS-Cov2 (COVID-19) acuciada por la actual pandemia mundial ha hecho crecer la preocupación acerca del perfil de seguridad o reacciones adversas de las mismas. Presentamos el caso de una paciente con antecedente reciente de neumonía por SARS-Cov2 que presentó reacción exantemática y tromboembolismo pulmonar tras ser inmunizada con la vacuna COVID-19 VaccineJanssen (Ad26.COV2-S).

\section{CASO CLÍNICO}

Se trata de una paciente de 75 años con antecedentes de hipertensión arterial e hipercolesterolemia que ingresó en nuestro centro por cuadro de neumonía bilateral por SARSCov2 (COVID-19) que evolucionó favorablemente con tratamiento con metilprednisolona a dosis de $1 \mathrm{mg} / \mathrm{kg} / \mathrm{día}$ y teicoplanina endovenosa durante 5 días a dosis de $400 \mathrm{mg} / \mathrm{dia}$. Al cabo de 20 días la paciente, ya sin síntomas, fue vacunada frente a COVID-19 con la vacuna Janssen COVID-19 Vaccine (Ad26.COV2-S). A las 48 horas de la vacunación la paciente comenzó con cuadro consistente en lesiones cutáneas pruriginosas generalizadas en tórax y abdomen, fiebre y dolor abdominal mal definido en región mesogástrica acompañado de vómitos de contenido alimentario, motivo por el que decide acudir a urgencias tras 24 horas de inicio de dicho cuadro. A su llegada presentaba tendencia a hipotensión (TA 62/42 mmHg), bradicardia a 44 Ipm y Ta 35,2 y saturación de 02 $96 \%$ basal. A la exploración física presentaba buen nivel de conciencia, estaba orientada en las 3 esferas, eupneica y con buena perfusión y coloración. No presentaba signos de trombosis venosa en miembros inferiores. La auscultación cardiaca y pulmonar y la exploración abdominal eran normales y destacaba la presencia de un exantema maculo-papuloso en tórax y abdomen (Imágenes 1,2 y 3). A nivel analítico podía observarse leucocitosis marcada $24.023 \mathrm{cel} / \mathrm{mm}^{3} \mathrm{con} 90 \%$ de segmentados, plaquetas de $323.000 \mathrm{cel} / \mathrm{mm}^{3}$ y PCR de $3,9 \mathrm{~g} / \mathrm{dl}$, sin otros hallazgos reseñables. Ante el cuadro de molestias abdominales con vómitos, leucotisosis e hipotensión se realizó un TC de abdomen que no mostró patología abdominal relevante pero sí como hallazgo no esperado una trombosis venosa profunda (TVP) en ambos miembros inferiores junto con un tromboembolismo pulmonar en la arteria lobar inferior izquierda e infartos pulmonares en lóbulo medio y lóbulo inferior izquierdo. Durante la estancia en urgencias

\section{ABSTRACT}

Several vaccines have appeared in recent times given the need for vaccinations against SARS-Cov2 (COVID-19) infection. General concern about their safety and possible adverse events has also emerged. We present the case of a patient with recent history of COVID-19 pneumonia who presented generalized exanthema and pulmonary embolism after being immunized withCOVID-19 Vaccine Janssen (Ad26.COV2-S).

la paciente mostró taquicardización, por lo que se realizó un electrocardiograma que mostraba una fibrilación auricular con respuesta ventricular acelerada entorno a $120 \mathrm{lpm}$.

Ante los hallazgos previamente mencionados la paciente ingresó en el servicio de medicina interna y se inició tratamiento anticoagulante con heparinas de bajo peso molecular y acenocumarol, así como metilprednisolona a dosis de $1 \mathrm{mg} /$ $\mathrm{kg}$ para el tratamiento del exantema y beta bloqueantes en dosis bajas como estrategia de control de frecuencia para la fibrilación auricular. Al cabo de 4 días de tratamiento esteroideo la paciente mostró remisión completa del exantema, mostrando ya desde el primer día una respuesta notable. Se completó el estudio con un perfil analítico de autoinmunidad que reveló ANA negativos, niveles de complemento C3 y C4 normales y niveles de inmunoglobulinas, G,M y A normales. Asimismo, se realizó un ecocardiograma que evidenciaba datos compatibles con hipertensión pulmonar con buena función de ambos ventrículos y sin valvulopatías significativas. La evolución clínica fue favorable y la paciente evoluciona favorablemente con rehabilitación de la marcha, pendiente de hacer seguimiento en consultas externas al alta hospitalaria.

\section{DISCUSIÓN}

En el último año desde el inicio de la pandemia COVID-19 hemos asistido a la emergencia de un número considerable de vacunas contra dicha infección ${ }^{1}$. La vacuna Ad26.COV2-S está basada en la replicación mediante un vector incompetente de adenovirus 26 que expresa la proteína de membrana del virus estabilizada y se administra en dosis única por vía intramuscular'. Los estudios de eficacia y seguridad se basan principalmente en los resultados preliminares de un ensayo clínico en fase $1 \|^{2}$ denominado COV3001. En dicho ensayo se observó una incidencia marcadamente mayor de eventos 
Fig. 1.
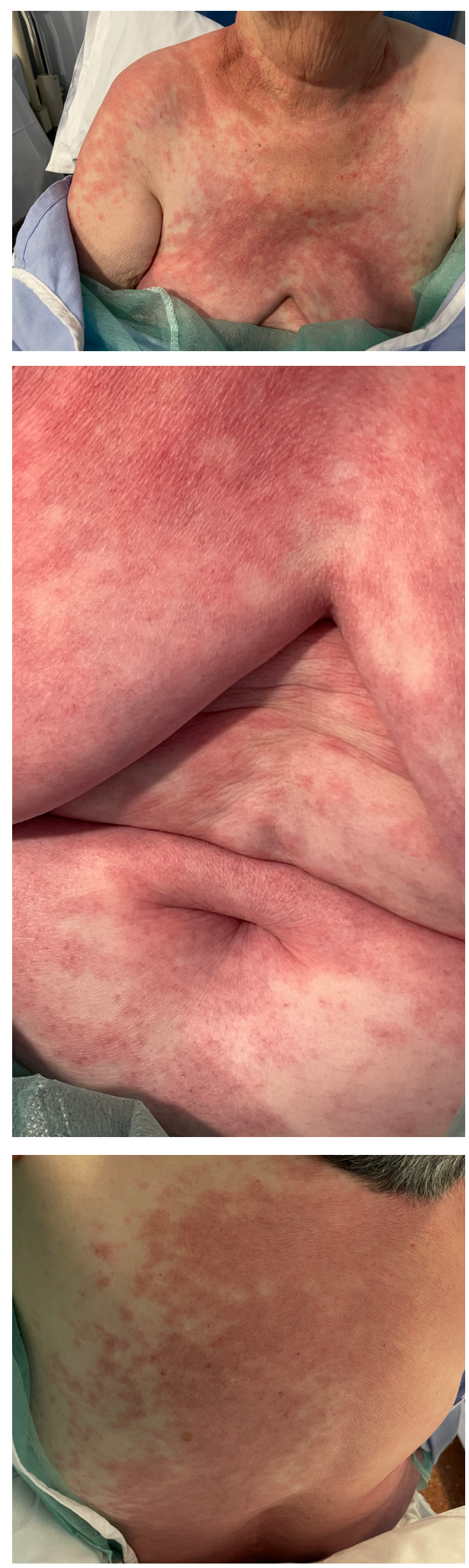

tromboembólicos venosos en pacientes que habían recibido la vacuna frente al grupo que recibió placebo (11 en el grupo de vacunación frente a 3 en placebo), si bien muchos de estos pacientes presentaban factores de riesgo como hipertensión arterial, obesidad o uso de anticonceptivos orales. En la mayoría de casos ocurridos en el ensayo, el tiempo desde la vacunación al diagnóstico fue superior a 10 días exceptuando 3 de ellos. El exantema generalizado o urticaria ha sido reportado como un efecto adverso poco frecuente en el estudio COV3001, sin detallar las características de los mismos.

Nuestra paciente presentaba como factores predisponentes a la trombosis su hipertensión arterial y movilidad reducida a consecuencia del deterioro general por la infección reciente. La propia COVID-19 se ha postulado como un factor protrombótico, asociado sobre todo a la fase agudade la infección en pacientes críticos, contribuyendo a un aumento de factores procoagulantes con una fisiopatología que se ha comparado a la de la coagulación intravascular diseminada ${ }^{3}$, no obstante algunos estudios muestran que la incidencia de eventos trombóticos tras el alta hospitalaria en pacientes sin otros factores de riesgo mayores no está incrementada ${ }^{4,5}$. Dada la escasa clínica en la esfera respiratoria y ausencia de clínica de TVP en la exploración, la trombosis podría haberse dado antes de la vacunación como consecuencia de la infección previa y la reducción de la movilidad.

En cuanto al exantema, la proximidad en el tiempo nos hace plantearnos la posibilidad de quese tratase de un rash postviral. Las lesiones maculo-papulosas generalizadas se han descrito como posible manifestación cutánea asociada a la COVID-19. En una cohorte de 375 pacientes que presentaron síntomas dermatológicos asociados a la infección por SARS-CoV2, las lesiones maculo-papulosas fueron las más frecuentes $(47 \%)^{6}$, si bien se presentaban mayoritariamente coincidiendo con el resto de síntomas y fase aguda de la infección, aunque se ha descrito que las manifestaciones cutáneas podrían aparecer hasta 30 días después de la fase aguda de la COVID-197.

\section{BIBLIOGRAFÍA}

1. Uptodate (Internet) Kathryn M Edwards WAO. Vaccines to prevent SARS-CoV-2 infection. (Cited May $6^{\text {th }}$ 2021). Available from: https://www.uptodate.com/ contents/covid-19-vaccines-to-prevent-sars-cov-2-infection

2. Sadoff J, Gray G, Vandebosch A, et al. Safety and Efficacy of Single-Dose Ad26. COV2.S Vaccine against Covid-19. N Engl J Med. 2021 April 21st. 2021 Apr 21. Online ahead of print.

3. Connors JM, Levy JH. Thromboinflammation and the hypercoagulability of COVID囚19. J Thromb Haemost. 2020;18(7):1559-1561.

4. Roberts LN, Whyte MB, Georgiou L, et al. Postdischarge venous thromboembolism following hospital admission with COVID-19. Blood. 2020;136(11):1347-1350.

5. Patell $R$, Bogue $T$, Koshy $A$, et al. Postdischarge thrombosis and hemorrhage in patients with COVID-19. Blood. 2020;136(11):1342-1346.

6. Galván Casas C, Català A, Carretero Hernández G, et al. Classification of the cutaneous manifestations of COVID $\otimes 19$ : a rapid prospective nationwide consensus study in Spain with 375 cases. Br J Dermatol. 2020;183(1):71-77.

7. Zhao Q, Fang X, Pang Z, Zhang B, Liu H, Zhang F. COVIDQ19 and cutaneous manifestations: a systematic review. J Eur Acad Dermatol Venereol. 2020;34(11):2505-2510. 